\title{
Surface roughness variation of thin wall milling, related to modal interactions
}

\author{
Sébastien Seguy*, Gilles Dessein, Lionel Arnaud \\ Laboratoire Génie de Production, École Nationale d'Ingénieurs de Tarbes, 47 Avenue d'Azereix, BP 1629, 65016 Tarbes Cedex, France
}

\begin{abstract}
High-speed milling operations of thin walls are often limited by the so-called regenerative effect that causes poor surface finish. The aim of this paper is to examine the link between chatter instability and surface roughness evolution for thin wall milling. Firstly, the linear stability lobes theory for the thin wall milling optimisation was used. Then, in order to consider the modal interactions, an explicit numerical model was developed. The resulting nonlinear system of delay differential equations is solved by numerical integration. The model takes into account the coupling mode, the modal shape, the fact that the tool may leave the cut and the ploughing effect. Dedicated experiments are carried out in order to confirm this modelling. This paper presents surface roughness and chatter frequency measurements. The stability lobes are validated by thin wall milling. Finally, the modal behaviour and the mode coupling give a new interpretation of the complex surface finish deterioration often observed during thin wall milling.
\end{abstract}

Keywords: Thin wall; Multimode; Milling; Chatter; Surface roughness; Stability lobes

\section{Contents}

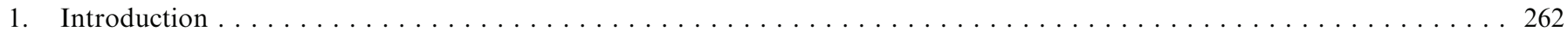

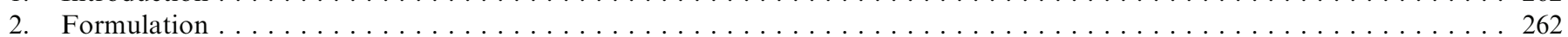

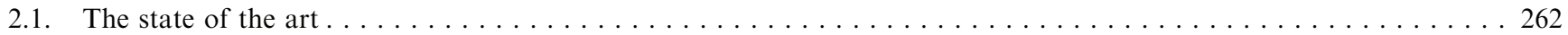

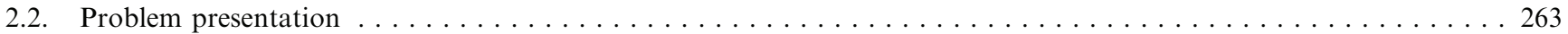

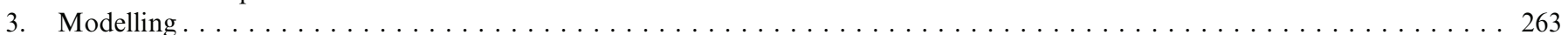

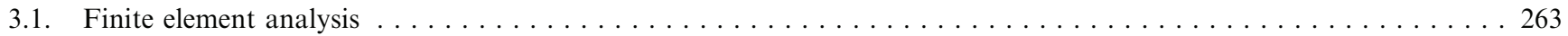

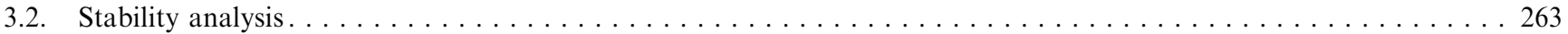

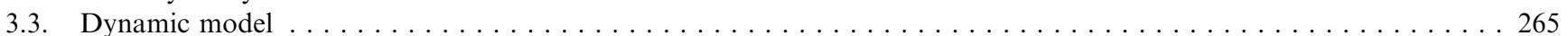

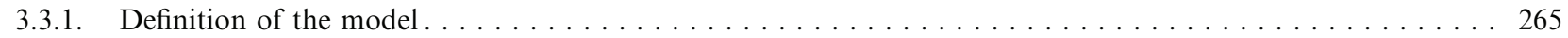

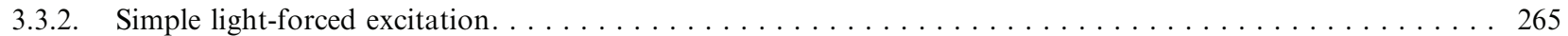

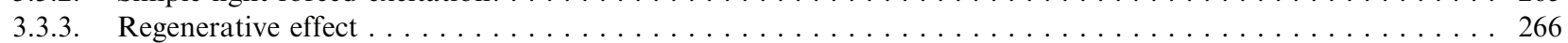

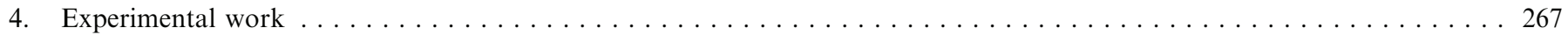

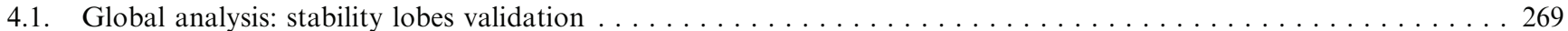

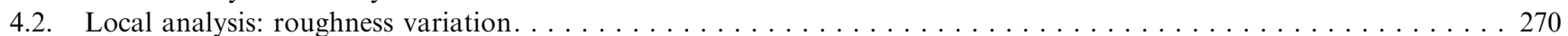

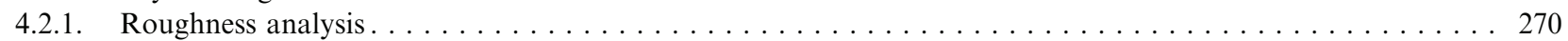

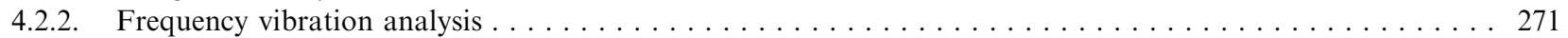

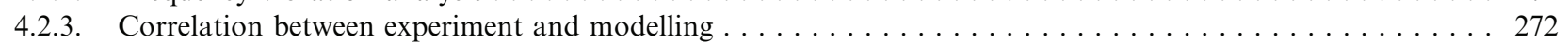

\footnotetext{
${ }^{*}$ Corresponding author. Tel.: + 33562442700 ; fax: +33562442708 .

E-mail address: sebastien.seguy@enit.fr (S. Seguy).
} 


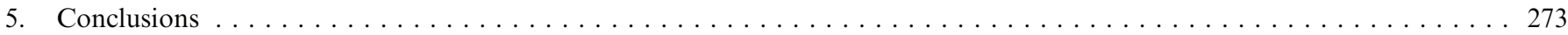

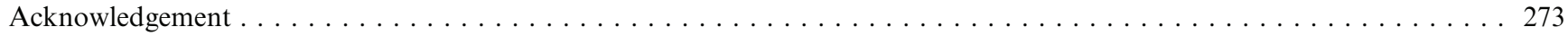

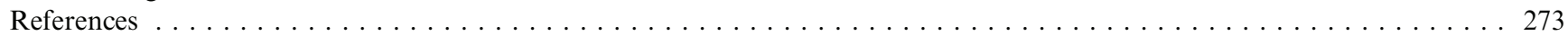

\section{Introduction}

Currently, machining by material removal constitutes one of the principal means of implementation for the mechanical parts. However, the more particular case of milling is the subject of many research works in order to improve its productivity. One of the most important factors affecting the performance of high-speed machining is the appearance of vibrations between the part and the tool. These regenerative vibrations appear when the machining system cannot follow the dynamics imposed by the cutting operation. Regenerative vibrations create chatter. Chatter not only limits the productivity of cutting processes, but also causes poor surface finish, reduces geometrical accuracy, increases the rate of tool wear [1] and reduces the life of the spindle.

Now, the tool vibrations are partially controlled by the use of the stability lobes, allowing to choose the spindle speed in order to limit the vibrations. However, the part vibrations are more difficult to control because the structures are changing during machining. It is the case in the thin wall machining. Thus on the milled walls a rapid change on the surface roughness [2], characteristic of chatter vibrations can be observed.

The aim of this paper is to examine the link between chatter instability and surface roughness evolution for thin wall milling. This complex phenomenon was highlighted and examined. The remainder of the paper is summarised as follows. Section 2 presents an overview of the state of the art in the thin wall milling modelling. The principle of the modelling and the calculation of the dynamic parameters are investigated in Section 3. Section 4 exposes the experimental work done to examine the complex surface finish. An interpretation of the relationship between chatter frequency and surface roughness is exposed. Comparisons between the modelling and the experimentation were also carried out in this section.

\section{Formulation}

\subsection{The state of the art}

The vibrations of the couple tool-part have been known since the years 1960. Tobias [3] and Tlusty [4] succeeded in explaining the causes of these regenerative vibrations in orthogonal cut, applied to turning. This knowledge is at the base of the stability lobes theory, which makes it possible to find the cutting depth of cut according to spindle speed, from which, the machining system will become unstable. In milling, cutting forces are difficult to define in a simple analytical form because the chip thickness is variable and the cut is discontinuous. A possible solution to this problem is to expand the cutting coefficients in a Fourier series. It is in the middle of the years 1990 that the first modelling in analytical form appeared [5,6]; this modelling is based on the mean value of the Fourier series. This approximation is useful, because it leads to a closed form expression for the stability lobes, the Hopf bifurcation. Finally, this theory is suitable for the vibrations of the tools, because the dynamic characteristics of the cutting tool do not change during the machining.

Chatter due to the excitation of the part has also been studied. Budak [7] studied not only the static deflexion of the wall but also developed a frequency domain simulation. In the thin wall case, this modelling cannot be applied directly, because the characteristics of the part strongly vary during machining $[8,9]$, in particular with the remove material. The stability lobes change during machining, what leads to the addition of the third dimension, corresponding to the tool position [10]. Bravo [11] extended this approach by considering the frequency response functions of both the machine and workpiece in the finishing operation. Milling of workpieces with low rigidity, like thin walls, implies to consider the static and dynamic effects and their evolution during the machining [12].

Recently, methods have been developed for the case of low radial depth of cut milling. Davies [13] and Gradisek [14] showed that those conditions generated new stable zones inside unstable zones, due to period-doubling vibrations, or Flip bifurcation. Recently, Zatarain [15] and Insperger [16] studied the influence of the tool helix angle on chatter stability. The helix angle does not affect the Hopf bifurcation, characterised by the zero-order solution $[5,6]$. On the other hand, the helix angle has a very important role on the Flip bifurcation, and perioddoubling instability areas are now closed islands, multiples of the tool helix pitch. Indeed, for axial depth of cut multiples of the helix pitch, the cut is much more continuous, the directional force coefficient becomes constant in time and Flip chatter cannot arise, see [16].

Moreover, the manufacturers are interested in having a prediction of the surface roughness of the finished part. The bibliography shows many methodologies and practices employed on this topic [17]. These methods make it possible to predict a surface quality by taking into account the influences of machining parameters, cutting tool properties, workpiece properties, etc. But only the sophisticated numerical simulation can study vibration in milling by generating the machined surface shape $[18,19]$. The surface shape prediction was only validated by experimental results on a simple mass-spring test bench [20]. 
Corduan [21] set up experimental tests coupled with numerical simulation in order to understand the link between the surface shape and chatter vibrations on thin walls. To this date, the author has concluded that on a real part with thin walls, the numerical simulation is not able to predict the surface shape correctly.

\subsection{Problem presentation}

In the aeronautical field, the thin walls are often presented in the form of blades for the composition of the turbo shaft engines. These are thin parts clamped on one direction, see Fig. 1. In this paper, thin wall in aluminium alloy 2017A was chosen, obtained by highspeed machining.

The dynamic properties of such a workpiece have many complexities. These parts have an infinity of modes, natural frequencies, stiffnesses, damping ratio and modal shapes.

In an industrial context, the problem of chatter is usually detected during the last step of the part development. In order to reduce the cost, it is very difficult to change at this time many parameters on the part manufacturing. The spindle speed is the simplest and the most effective parameter than can be adjusted. In this study, to approach the industrial context, except the spindle speed, all the parameters of the machining process were fixed: workpiece geometry (thin wall), tool, machining strategy, thickness to be removed, etc.

\section{Modelling}

\subsection{Finite element analysis}

Modelling by finite element using Ideas ${ }^{\circledR}$ software was implemented in order to obtain the dynamic characteristics of the thin wall. The thin wall is modelled by $2 \mathrm{D}$ plates, although a 3D model gives the same result. The mesh of the part has been done with a 6-node quadratic triangular element. A converging study on the natural frequency has shown that 653 nodes are sufficient, for a precision of $0.15 \%$. This

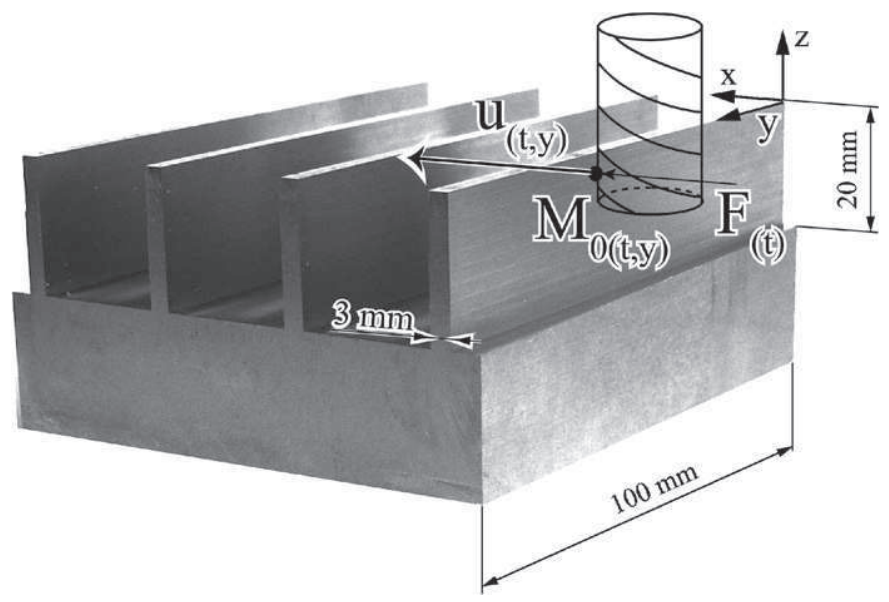

Fig. 1. Workpiece.

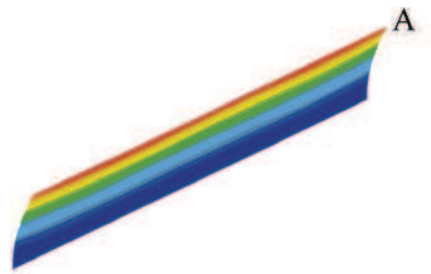

Mode 1: $5919 \mathrm{~Hz}$

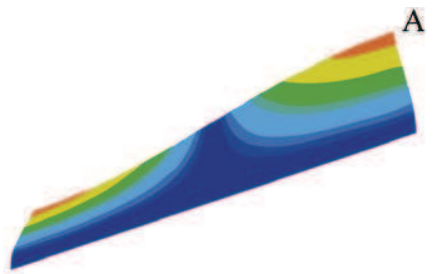

Mode 2: $6441 \mathrm{~Hz}$

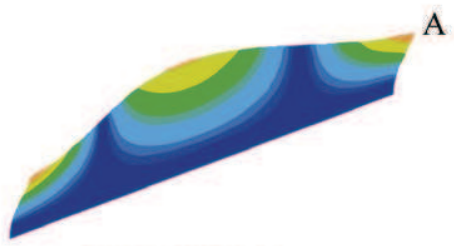

Mode 3: $8029 \mathrm{~Hz}$
Fig. 2. Modal shape and natural frequency for each mode.

Table 1

Dynamical parameters

\begin{tabular}{llll}
\hline Mode & $f_{0}(\mathrm{~Hz})$ & $k(\mathrm{~N} / \mathrm{m})$ & $\xi(\%)$ \\
\hline 1 & 5919 & $5.8 \times 10^{6}$ & 0.16 \\
2 & 6441 & $3.4 \times 10^{6}$ & 0.11 \\
3 & 8029 & $4.4 \times 10^{6}$ & 0.07 \\
\hline
\end{tabular}

modelling makes it possible to calculate the natural frequency $\left(f_{0}\right)$ and the modal stiffness $(k)$. The modal stiffnesses calculated here, corresponds to the most flexible point: A, the free corner of the wall, see Fig. 2. On the normalised modal shapes $\Phi_{1}(y), \Phi_{2}(y)$ and $\Phi_{3}(y)$ relative to the mode 1,2 and 3 , it is easy to see the nodes and antinodes of each mode, see Fig. 2. Then, hammer impact was conducted in order to adjust the model to the real behaviour of the thin wall. The damping ratio $(\xi)$ was obtained by hammer impact because it is almost impossible to predict. The dynamic parameters of the thin wall are summarised in Table 1.

\subsection{Stability analysis}

From the dynamic characteristics obtained by calculations and validated by tests, machining stability can be studied. To do this, the classical model used for the thin wall will be presented.

This paper focuses on the peripheral finishing of a thin wall. In this case, the helix pitch is small (small diameter of the tool and large helix angle), the Flip areas are negligible, and the authors [16] find the classical lobes characterised by the Hopf bifurcation, see Section 2.1.

In this case, the model based on the work of Altintas and Budak $[5,6]$ is appropriate. The topic of the following is to present the result of this model. In order to apply this modelling, the main assumptions are the following:

- the tool is rigid compared with the workpiece, which is considered to be globally flexible, but rigid in the cutting zone, 


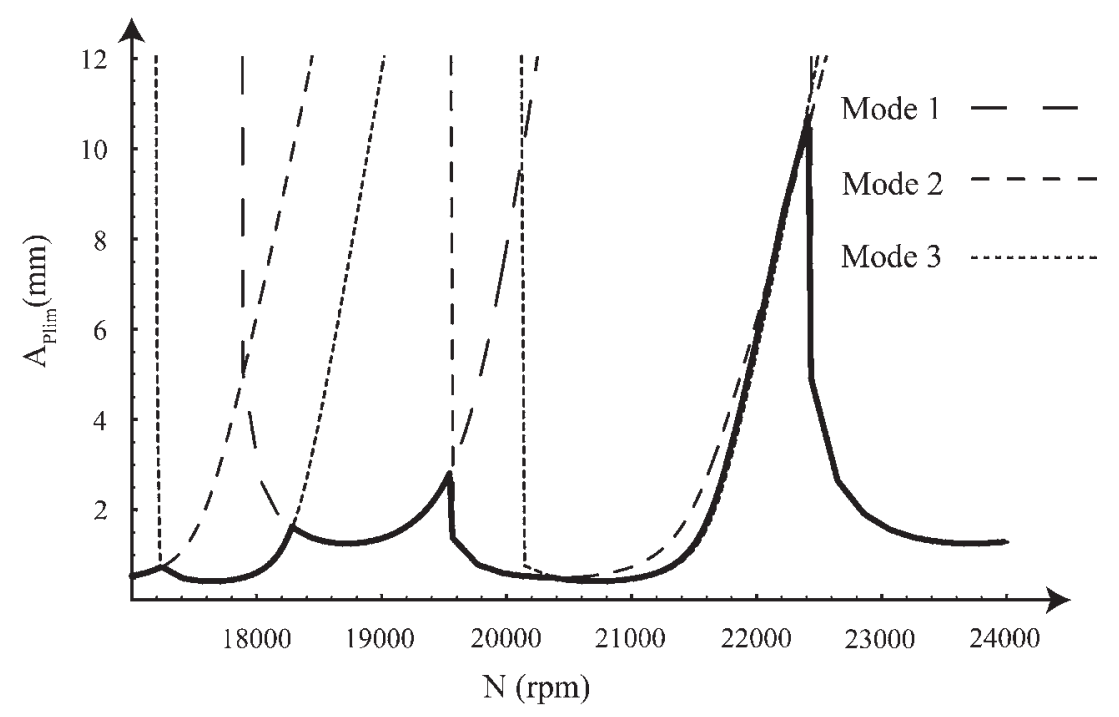

Fig. 3. Stability chart.

- the workpiece moves along the $x$ direction only (Fig. 1), like a single degree of freedom,

- the transfer function of the part in the $x$ direction is

$G_{x}\left(\mathrm{i} \omega_{\mathrm{c}}\right)=\frac{\omega_{0}^{2}}{k\left(\omega_{0}^{2}-\omega_{\mathrm{c}}^{2}+2 \xi \omega_{0} \omega_{\mathrm{c}} \mathrm{i}\right)}, \mathrm{i}^{2}=1$,

where $k, \xi$ and $\omega_{0}$ are, respectively the stiffness, damping ratio and natural pulsation of the workpiece. Here, $\omega_{\mathrm{c}}$ is the chatter frequency.

The following linear cutting law was used: $F_{\mathrm{T}}=$ $K_{\mathrm{T}} A_{\mathrm{P}} h(t)$ and $F_{\mathrm{R}}=k_{\mathrm{r}} F_{\mathrm{T}}$, where $F_{\mathrm{T}}$ and $F_{\mathrm{R}}$ are, respectively the tangential and radial cutting forces, $K_{\mathrm{T}}$ and $k_{\mathrm{r}}$ are the corresponding tangential milling force coefficient and radial force coefficient ratio, $A_{\mathrm{P}}$ is the axial depth of cut and $h(t)$ is the chip thickness. The cutting force coefficients were chosen in coherence with the bibliography [14].

Our goal is to choose spindle speeds in order to facilitate the stability or instability of the system; the results using the stability lobes theory will be given directly. According to [6], the axial depth of cut limit is expressed in the form

$A_{\mathrm{P} \lim }=\frac{1}{(z / 2 \pi) \alpha_{x x} K_{\mathrm{T}} \Re e\left[G_{x}\left(\mathrm{i} \omega_{\mathrm{c}}\right)\right]}$,

where $z$ is the number of teeth and $\alpha_{x x}$ the directional milling coefficient

$\alpha_{x x}=\frac{1}{2}\left[-\cos (2 \theta)-2 \theta k_{\mathrm{r}}-k_{\mathrm{r}} \sin (2 \theta)\right]_{\phi_{\mathrm{st}}}^{\phi_{\mathrm{ex}}}$,

$\left\{\begin{array}{c}\phi_{\mathrm{st}}=\arccos \left(\frac{2 A_{\mathrm{E}}}{D}-1\right) \\ \phi_{\mathrm{ex}}=\pi\end{array}\right.$,

where $\theta$ is the tool angle engagement, $D$ the tool diameter, $A_{\mathrm{E}}$ the radial depth of cut, $\phi_{\mathrm{ex}}$ and $\phi_{\mathrm{st}}$ the down milling exit and start angle, respectively.
$\Re e\left[G_{x}\left(\mathrm{i} \omega_{\mathrm{c}}\right)\right]$ is the real part of the structural transfer function of a system with one degree of freedom:

$\Re e\left[G_{x}\left(\mathrm{i} \omega_{\mathrm{c}}\right)\right]=\frac{1}{k} \frac{1-d^{2}}{\left(1-d^{2}\right)^{2}-4 \xi^{2} d^{2}} ; \quad d=\frac{\omega_{c}}{\omega_{0}}$.

The link between the chatter frequency $\omega_{\mathrm{c}}$ and the spindle speed $N$ is

$N=\frac{60 \omega_{\mathrm{c}}}{z\left[2 m \pi+2 \pi-2 \arctan \left(\left(d^{2}-1\right) /(2 \xi d)\right)\right]}$.

Eqs. (2) and (5) constitute a system of parameterised equations $\left\{A_{\mathrm{P}}\left(\omega_{\mathrm{c}}\right), N\left(\omega_{\mathrm{c}}\right)\right\}_{m}$, with $m$ an integer corresponding to the number of full vibration cycles between two teeth.

The natural modes of vibration are considered to be uncoupled. This calculation is applicable to each natural mode of vibration of the workpiece. In this case, the material removed is small and the dynamic parameters are considered constant. The graph, thus obtained is the minimum of the graphs obtained for each mode, see Fig. 3. The cutting parameters used for this plot are: down milling, $A_{\mathrm{E}}=0.2 \mathrm{~mm}, K_{\mathrm{T}}=400 \mathrm{MPa}, k_{\mathrm{r}}=0.1, D=12 \mathrm{~mm}, z=4$ and the modal parameters of Table 1 . For a $10 \mathrm{~mm}$ axial depth of cut, the resulting layout shows an optimal spindle speed at $22250 \mathrm{rpm}$, and a more unstable machining speed at $N=20500 \mathrm{rpm}$. The stability limit of the second and the third modes is exceeded, and these modes must vibrate during the machining test. However with this classical model, the modes are uncoupled and it is impossible to predict the ever-changing predominant mode, and the ploughing effect.

In conclusion, with the stability chart obtained only a stable or unstable cutting condition can be chosen. For unstable machining $\left(A_{\mathrm{P}}=10 \mathrm{~mm}\right.$ and $\left.N=20500 \mathrm{rpm}\right)$, the stability lobes do not model either the mode coupling or 
the ploughing effect, only the modes, which vibrate are found.

\subsection{Dynamic model}

This section presents how the specificities of the thin walls can be taken into account. How the modal shape can reveal or make chatter frequencies disappear will be shown. A dynamic model is defined considering:

- the regenerative effect of the cut,

- the modal shape of each mode,

- the nonlinearity when the tool leaves the cut and

- the ploughing effect.

The main objective is to propose an explanation for surface roughness variation observed during the test presented in Section $4.2\left(A_{\mathrm{P}}=10 \mathrm{~mm}\right.$ and $\left.N=20500 \mathrm{rpm}\right)$.

\subsubsection{Definition of the model}

To simplify the model in this paper, it was assumed here that: the variation of displacement along the $z$-axis, in the cutting zone, is supposed to be constant.

The limit given by the stability lobe of the first mode is never exceeded for the cutting condition used during the test. This is explained by the natural frequency of this mode compared with the tooth-passing excitation but also by his higher stiffness and damping. Moreover, the experimental test does not show the contribution of this mode. Finally, the first mode is neglected and only the two modes appearing during the machining test, the second and the third one, are taken into consideration.

It can be assumed that the tool is moving along the workpiece at uniform speed $V$, and the displacement of a point $M_{0(t, y)}$, is $u_{(t, y)}$ with $y=V t$, see Fig. 1 . The modal representation is used to decompose this displacement:

$u_{(t, y)}=\Phi_{2}(y) q_{2}(t)+\Phi_{3}(y) q_{3}(t)$

with $\left\{\Phi_{2}(y), \Phi_{3}(y)\right\}$ the modal shapes associated with the corresponding natural undamped pulsations $\omega_{2}=$ $\sqrt{k_{2} / m_{2}}, \quad \omega_{3}=\sqrt{k_{3} / m_{3}},\left\{q_{2}(t), q_{3}(t)\right\}$ the modal weights functions that are solutions of the modal differential equations associated with each vibrating mode

$\left\{\begin{array}{l}m_{2} \ddot{q}_{2}(t)+c_{2} \dot{q}_{2}(t)+k_{2} q_{2}(t)=f_{2}(t)=\Phi_{2\left(M_{\mathrm{O}}\right)} F(t), \\ m_{3} \ddot{q}_{3}(t)+c_{3} \dot{q}_{3}(t)+k_{3} q_{3}(t)=f_{3}(t)=\Phi_{3\left(M_{\mathrm{O}}\right)} F(t),\end{array}\right.$

where $m_{2}, m_{3}$ are the modal masses; $c_{2}=2 \xi_{2} \sqrt{k_{2} m_{2}}, c_{3}=$ $2 \xi_{3} \sqrt{k_{3} m_{3}}$ are the modal damping coefficients; $k_{2}, k_{3}$ are the modal stiffnesses and $F(t)$ is the cutting force considered at the point $M_{0}$.

The cutting force depends on instantaneous cutting condition, the following form can be assumed:

$F(t)=\left[g(t)+K_{2} h(t)\right] r(h(t))$,

where $g(t)$ represent a light-forced excitation, like a noise function, the exact level or shape of this function is not very significant but the model needs such noise to let the chatter start. In order to simplify the presentation in this paper, the following form $g(t)=K_{1} \sin \left(\omega_{\mathrm{D}} t\right)$ is considered, with $K_{1}$ a small force coefficient and $\omega_{\mathrm{D}}$ the tooth-passing pulsation. It is possible to take into account harmonics of a higher order, but the simulation has shown little influence, this function is just a perturbation.

The $K_{2}$ coefficient corresponds to the cutting coefficient applied for the milling process, $h(t)$ is the chip thickness and can be approximated by $h(t)=f_{\mathrm{z}}+u(t-\tau)-u(t)$, with $f_{\mathrm{z}}$ the feed per tooth and $u(t-\tau)$ the delayed term linked to the regenerative effect. In fact, a linear cutting law was used, where the cutting forces are proportional to the static $\left(f_{\mathrm{z}}\right)$ and dynamic $(u(t-\tau)-u(t))$ chip thickness.

In real machining, the tool vibrations still have finite amplitude. When the vibrations are too strong, the tool leaves the cut, and no effort is applied during this time. In order to model this, a unit function $r(h(t))$ was introduced. It can be described as follows:

- when $h(t) \leqslant 0, r(h(t))=0$, the cutting forces are nil, and no effort is applied,

- when $h(t)>0, r(h(t))=1$, the cutting forces are calculated by a linear cutting law.

In the thin wall milling the effect of the ploughing is very important. Due to vibrations of the workpiece, the clearance face of the tool is in contact with the material, this ploughing effect increases the damping process and limits the vibrations. In this modelling, the damping process can be divided as follow:

- structural damping, measured by hammer impact and

- high damping when the ploughing effect is detected.

The occurrence of ploughing is detected when the angle formed between the cutting speed $V_{\mathrm{c}}$ and the speed of vibration $\partial u(t, y) / \partial t$, is higher than the clearance angle. Then, the ploughing effect is modelled by increasing artificially the structural damping by 500 (for the second mode, for example, without ploughing $\xi_{2}=0.11 \%$ and with ploughing $\xi_{2}=55 \%$ ). The value of the high damping linked to the ploughing effect was determined by simulation. Indeed, with a much smaller value, the clearance angle condition is not respected at all and with a greater value the result is similar but computation time increases drastically.

\subsubsection{Simple light-forced excitation}

This section presents only the light-forced excitation with $K_{1}=1 \mathrm{~N}, K_{2}=0$ and $r(h(t))=1$. The tooth-passing pulsation $\omega_{\mathrm{D}}=8586 \mathrm{rad} / \mathrm{s}$ corresponds to the test studied in Section 4.2. These assumptions are preliminary here in order to understand the modal shape effect on the system response. Now, Eq. (7) is rewritten as below

$\left\{\begin{array}{l}m_{2} \ddot{q}_{2}(t)+c_{2} \dot{q}_{2}(t)+k_{2} q_{2}(t)=\Phi_{2(V t)} K_{1} \sin \left(\omega_{\mathrm{D}} t\right), \\ m_{3} \ddot{q}_{3}(t)+c_{3} \dot{q}_{3}(t)+k_{3} q_{3}(t)=\Phi_{3(V t)} K_{1} \sin \left(\omega_{D} t\right) .\end{array}\right.$ 
The modes shapes are known by finite element analysis. Moreover, it is assumed that, because of the small amount of removed material during the final machining operation, the modal basis was considered as fixed during the operation. This assumption has been verified both by calculus and experimentally. Eq. (9) can be analytically or numerically solved with the values given in Table 2. Fig. 4 presents the system response. Nodes and antinodes appear clearly in the modal shape.

Table 2

Modal parameters values for resolution

\begin{tabular}{ll}
\hline Parameters & Values \\
\hline$m_{2}$ & $0.002075 \mathrm{~kg}$ \\
$m_{3}$ & $0.001728 \mathrm{~kg}$ \\
$c_{2}$ & $0.1847 \mathrm{~N} \mathrm{~s} / \mathrm{m}$ \\
$c_{3}$ & $0.1220 \mathrm{~N} \mathrm{~s} / \mathrm{m}$ \\
$k_{2}$ & $3.4 \times 10^{6} \mathrm{~N} / \mathrm{m}$ \\
$k_{3}$ & $4.4 \times 10^{6} \mathrm{~N} / \mathrm{m}$ \\
\hline
\end{tabular}

In Fig. 4, the transient was observed at the beginning and at the end ( $t=0$ and $1.5 \mathrm{~s})$. This transitory time can be easily quantified, for example the time-constant for the second mode is $\tau_{2}=1 /\left(\xi_{2} \omega_{2}\right)=22 \mathrm{~ms}$. Generally the end of transient occurred after $3 \tau_{2}(95 \%)$, so approximately $66 \mathrm{~ms}$.

When passing on a node, excitation decreases, its signs change and its phase shifts by $180^{\circ}$, which forces the system to follow the excitation. There is a shift time between node passing and nil response, $1 \mathrm{~ms}$.

In this study, the transitory effects disappear very quickly and have no significant effect on the response, only at the beginning and at the end. In this section, the modes are uncoupled, each mode reacting to the force without any cross effect, and the two responses are independent. In conclusion, this first approach showed how the modal shapes affect the response system: on a node the considered mode is not excited.

\subsubsection{Regenerative effect}

In order to model a real milling process, a technique modelling the forced vibration and the regenerative effect
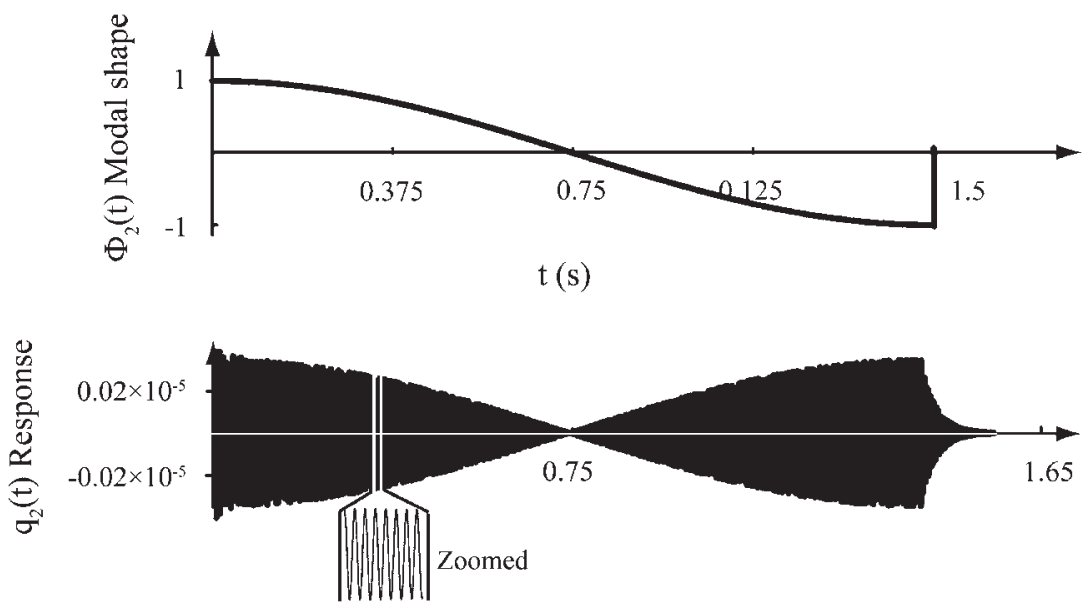

$t(s)$
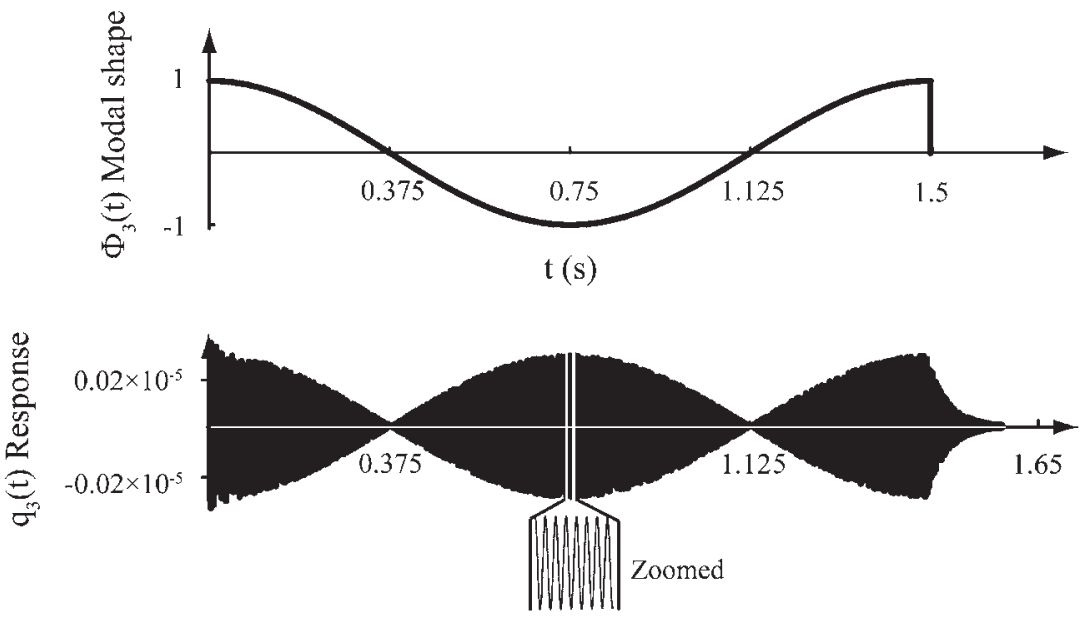

$\mathrm{t}(\mathrm{s})$

Fig. 4. Effect of a simple forced excitation on the system response. 
was presented. This model is made in order to show the mode coupling due to the regenerative effect. The modal equations were rewritten with Eqs. (7) and (8): amplitude increases rapidly. At $t=0.90 \mathrm{~s}$, the amplitude of mode 3 decreases due to the approach towards the node. Between $t=0.90$ and $1.12 \mathrm{~s}$, a transition zone is still

$$
\left\{\begin{array}{c}
m_{2} \ddot{q}_{2}(t)+c_{2} \dot{q}_{2}(t)+k_{2} q_{2}(t)=\Phi_{2(V t)}\left\{K_{1} \sin \left(\omega_{\mathrm{D}} t\right)+K_{2}\left[f_{z}+u(t-\tau)-u(t)\right]\right\} r(h(t)), \\
m_{3} \ddot{q}_{3}(t)+c_{3} \dot{q}_{3}(t)+k_{3} q_{3}(t)=\Phi_{3(V t)}\left\{K_{1} \sin \left(\omega_{\mathrm{D}} t\right)+K_{2}\left[f_{z}+u(t-\tau)-u(t)\right]\right\} r(h(t)) .
\end{array}\right.
$$

Introducing Eq. (6) in Eq. (10), the following equation is obtained: observed, with low amplitude vibrations.

At $t=1.12 \mathrm{~s}$, the excitation approaches a node of mode

$\left\{\begin{array}{l}m_{2} \ddot{q}_{2}(t)+c_{2} \dot{q}_{2}(t)+k_{2} q_{2}(t)=\Phi_{2(V t)}\left\{K_{1} \sin \left(\omega_{\mathrm{D}} t\right)+K_{2}\left[f_{\mathrm{z}}+\Phi_{2(V t)}\left(q_{2}(t-\tau)-q_{2}(t)\right)+\Phi_{3(V t)}\left(q_{3}(t-\tau)-q_{3}(t)\right)\right]\right\} r(h(t)) \\ m_{3} \ddot{q}_{3}(t)+c_{3} \dot{q}_{3}(t)+k_{3} q_{3}(t)=\Phi_{3(V t)}\left\{K_{1} \sin \left(\omega_{\mathrm{D}} t\right)+K_{2}\left[f_{\mathrm{z}}+\Phi_{2(V t)}\left(q_{2}(t-\tau)-q_{2}(t)\right)+\Phi_{3(V t)}\left(q_{3}(t-\tau)-q_{3}(t)\right)\right]\right\} r(h(t)) .\end{array}\right.$

The light-forced excitation is modelled with the coefficient $K_{1}=1 \mathrm{~N}$. The cutting force coefficient is modelled by $K_{2}=1 / 2 K_{\mathrm{T}} A_{\mathrm{P}} \alpha_{x x}$ with $K_{\mathrm{T}}=800 \mathrm{MPa}, A_{\mathrm{P}}=10 \mathrm{~mm}, k_{\mathrm{r}}=$ 0.1 , and $\alpha_{x x}=-0.116$ see Eq. (3), then $K_{2}=-4.6 \times 10^{5} \mathrm{~N} / \mathrm{m}$. The $K_{\mathrm{T}}$ coefficient was slightly increased in order to take into account the nonlinearity of the cutting law when the tooth feed is near the radial depth of cut [8]. The time delay $\tau$ is equal to the tooth-passing period $\tau=60 /(\mathrm{Nz})=$ $7.3 \times 10^{-4} \mathrm{~s}$, where $N$ is the spindle speed in $\mathrm{rpm}$ and $z$ is the number of teeth of the tool. In this case, the test presented in Section 4.2 was modelled with $N=20500 \mathrm{rpm}$ and $z=4$. The cutting speed is $V_{\mathrm{c}}=N \pi D / 60=12.88 \mathrm{~m} / \mathrm{s}$, the clearance angle is $4^{\circ}$ and the ploughing effect is modelled by a damping increase of 500 .

The system of nonlinear delayed differential Eq. (11), does not have an analytical solution; a numerical resolution was used, with the coefficients of Table 2. The numerical calculus is done with Matlab ${ }^{\circledR}$ software, using the dde 23 routine (delay differential equations). The scalar relative error tolerance parameter is $1 \times 10^{-3}$ and the absolute error tolerance is $1 \times 10^{-6}$. The results of this numerical integration are presented in Fig. 5. The modal shapes $\Phi_{2}(y)$ and $\Phi_{3}(y)$ of modes 2 and 3, the modal weights functions $q_{2}(t)$ and $q_{3}(t)$ solutions of the Eq. (11), the displacement $u_{(t, y)}$, and the displacement $u_{(t, y)}$ sampled at the tooth-passing frequency can be found.

Near $t=0 \mathrm{~s}$, according to the previous section, the two modes could vibrate because the excitation is on an antinode. An increase in the second-mode amplitude is observed, probably because it has the least stiffness. By introducing other disturbing excitations, this can always be observed. Then mode 2 vibrates strongly from the regenerative effect, linked to mode coupling, the third mode is also excited, but its amplitude is less important.

At $t=0.5 \mathrm{~s}$, mode 2 approaches on this node, it is then slightly excitable, and its amplitude decrease rapidly. Between $t=0.5$ and $0.7 \mathrm{~s}$, the modelling showed a transition zone, with low amplitude vibrations.

Near $t=0.7 \mathrm{~s}$, the excitation is on the antinode of the third mode. At this time, it is more excitable, and its
3 , which is no longer excited. Then, mode 2 can start to vibrate and prevents mode 3 from resuming to vibrate even if it is not on its node.

The displacement of the part sampled at the toothpassing frequency indicates that when the amplitude of the vibrations is too strong there is no regular pattern, which is characteristic of a strongly unstable machining. However, this representation gives a first indication of the displacements at the scale of the tooth pass and thus an image of corresponding roughness.

In this section, a dynamic model based on the regenerative effect is presented. In this simple modelling, most of the coefficients are given by the mechanical characteristics. This modelling shows an original behaviour: the mode, which is vibrating dominates the other modes. The dominating mode dies out only near its node. On the sample, these changes can affect the surface roughness. This approach will be validated in the experimental part.

\section{Experimental work}

The cutting tests were carried out on a 3-axis high-speed milling centre, with a $24000 \mathrm{rpm}$ spindle. The tool was a carbide cylindrical end mill with four cutting edges, $12 \mathrm{~mm}$ diameter, $45^{\circ}$ helix angle, $0.15 \mathrm{~mm}$ corner radius, and $L=36 \mathrm{~mm}$ overhang $(L / D=3)$. A small overhang is necessary to consider a rigid cutter on the spindle. The tool static stiffness $\left(42.5 \times 10^{6} \mathrm{~N} / \mathrm{m}\right)$ is at least 20 times higher than the thin wall static stiffness $\left(2.05 \times 10^{6} \mathrm{~N} / \mathrm{m}\right)$. The cutter was mounted in a HSK 63A shrink fit holder. In this case, the workpiece stiffness is very low and the tool holder is not an important point; the tool holder in a grip fit gives the same results.

The workpiece was made of 2017A aluminium alloy. The machining of the thin wall starts from a solid block, see Fig. 6. This organisation allows great accuracy on the wall dimensions. Moreover, there is no improbability on the wall fixtures and all the walls have the same dynamic behaviour, in particular the damping ratio. 

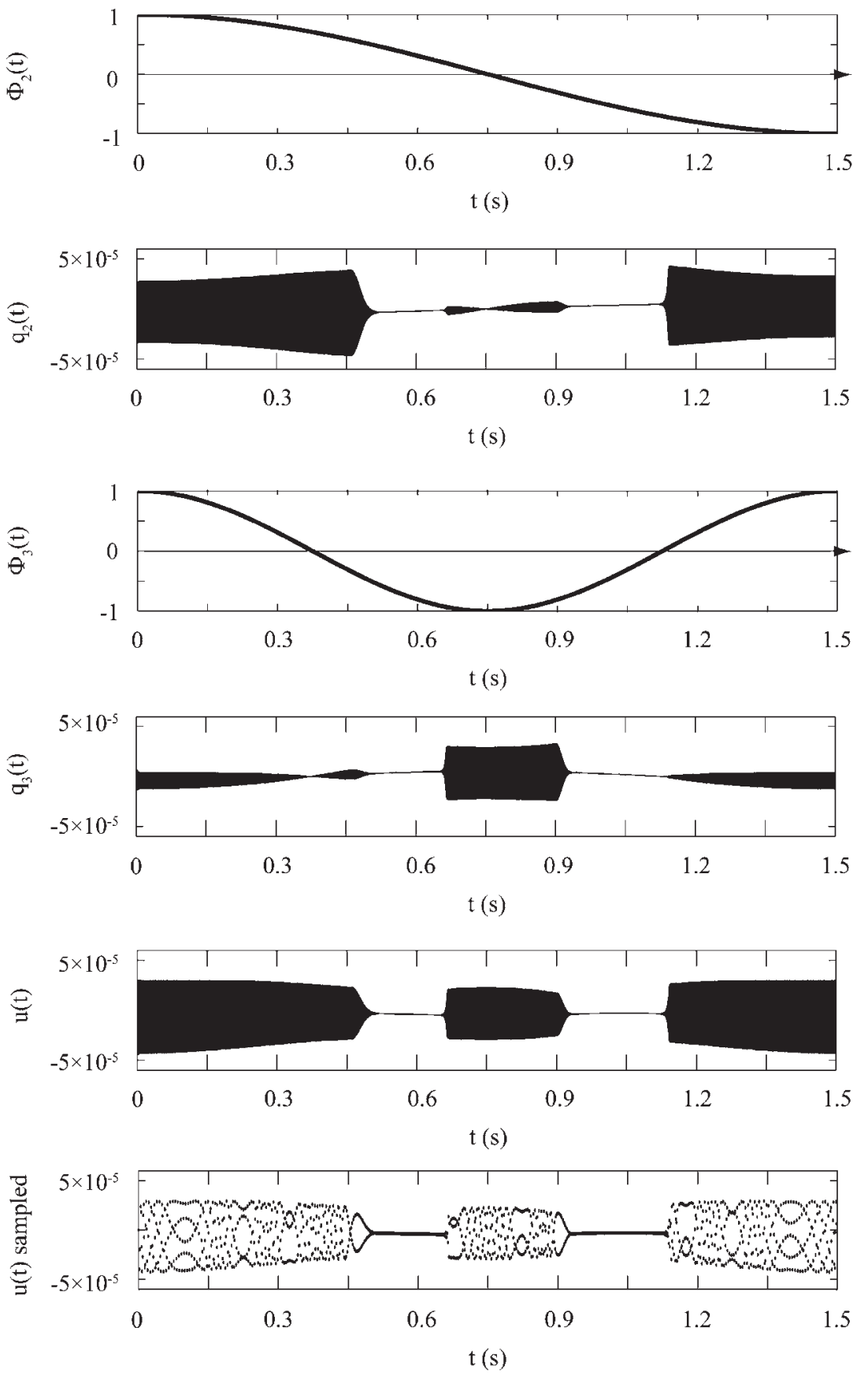

Fig. 5. Displacement computed for a real machining test.

Vibrations of the part were measured in the $x$ direction, the perpendicular feed direction, by a laser vibrometer without contact (produced by Ometron, $\mathrm{VH} 300+$ ). The laser beam focussed on the side of the wall where the tool stands, and the spot of the laser is fixed on a position, it does not move with the tool. The spot size of the laser is approximately $1 \mathrm{~mm}$, in order to average the scale of the surface roughness. The laser beam is easy to use in an industrial environment because it is without contact. Machining does not need coolant fluid; moreover lubrication does not disturb the laser signal. It is however compatible with micro lubrication.
There are various simple surface roughness parameters used in industry [22], such as roughness average $(\mathrm{Ra})$, rootmean-square roughness $(\mathrm{Rq})$, maximum height of the profile (Rt), average maximum height of the profile (Rz), etc. The three dimensions criteria such as $\mathrm{sRa}$, sRt, seem promising [23], because they give a complete view of the surface, but they are not widely used in industry. In this study, the parameters $2 \mathrm{D}, \mathrm{Ra}$ and Rt are used, and well correlated with 3D parameters. A pocket surf stylus type instrument (produced by Hommel, Powerpack P500) is used in this study due to its easy setup. A 3D profilometer (produced by Optical Profil, WYKO NT 1100) was also 


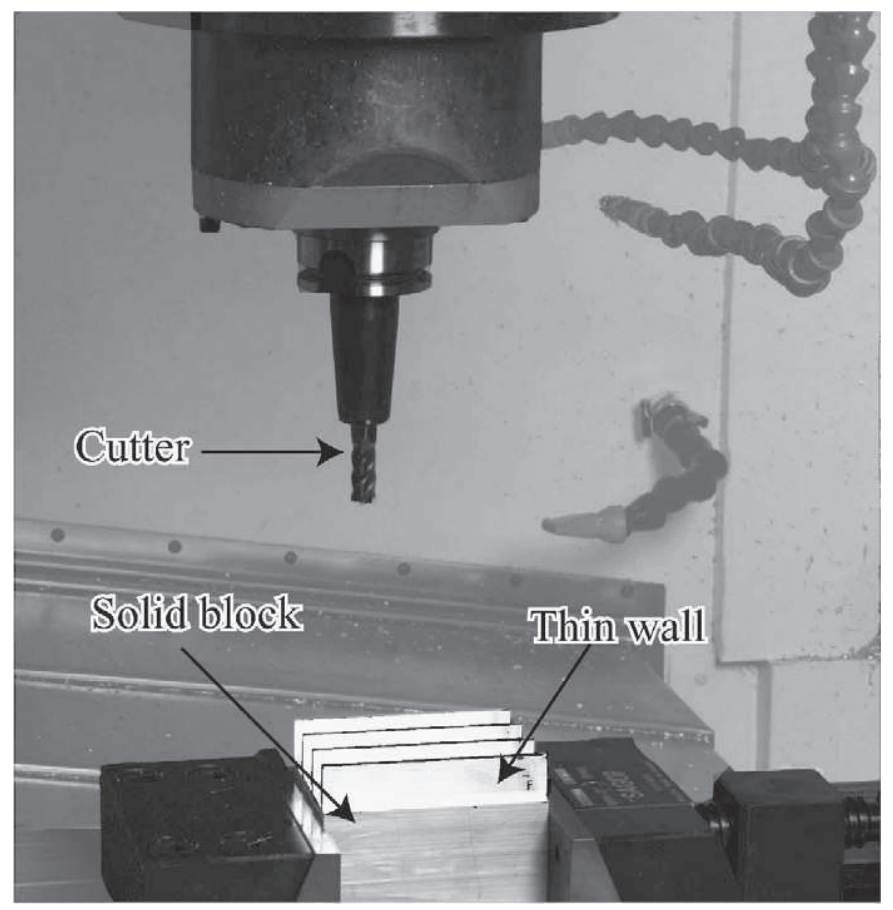

Fig. 6. Machining set up.

used. This $3 \mathrm{D}$ measurement makes it possible to check the results easily obtained in $2 \mathrm{D}$ by surfing stylus. It also enables better understanding of the machined surface, by $3 \mathrm{D}$ views.

The thin wall was down-milled in finishing, with an axial depth of cut of $10 \mathrm{~mm}$, a radial depth of cut of $0.2 \mathrm{~mm}$ and a feed rate of $0.05 \mathrm{~mm} /$ tooth. Three thin walls were machined with three spindle speeds: 24000, 20500 and $22250 \mathrm{rpm}$. The first spindle speed $(24000 \mathrm{rpm})$ results from the recommendations of the tool manufacturer, but leads to strong vibration. The second (20500 rpm) corresponds to an arbitrary reduction of $15 \%$ in order to reduce the vibration. The last (22 $250 \mathrm{rpm})$ is selected by using the stability lobes; see optimal windows in the stability chart Fig. 3.

\subsection{Global analysis: stability lobes validation}

Three walls are milled with the spindle speeds previously presented. In order to evaluate the surface quality, the maximal roughness can be studied. The surface roughness measurement shown here corresponds to the worst surface finish of each workpiece. The results are given in Table 3 . In order to check the homogeneity of the surface, the roughness measurement was made according to four lines (Fig. 7). The measurements, repeated three times, are equivalent, and the values presented are the average of these measurements.

The results in directions $1,2,3$ and 4 are in the same order of magnitude. However, it is noted that roughness according to direction 1 is slightly higher. This direction is on the top of the clamped wall; therefore under the effect of
Table 3

Maximal roughness ( $\mathrm{Ra}, \mathrm{Rt})$

\begin{tabular}{lllll}
\hline Spindle speed $(\mathrm{rpm})$ & Direction & $\mathrm{Ra}(\mu \mathrm{m})$ & $\mathrm{Rt}(\mu \mathrm{m})$ & $\mathrm{Rt} / \mathrm{Ra}$ \\
\hline 24000 & 1 & 7.0 & 35.2 & 5 \\
& 2 & 6.7 & 34.4 & 5.7 \\
& 3 & 6.6 & 32.0 & 4.8 \\
& 4 & 5.7 & 29.5 & 5.1 \\
2250 & 1 & 3.2 & 10.9 & 3.4 \\
& 2 & 3.0 & 10.2 & 3.4 \\
& 3 & 3.0 & 10.0 & 3.3 \\
& 4 & 2.9 & 11.0 & 3.7 \\
& 1 & 7.5 & 35.4 & 4.7 \\
& 1 & 7.6 & 34.4 & 4.5 \\
& 2 & 7.0 & 34.6 & 4.9 \\
& 3 & 5.8 & 28.8 & 4.9 \\
\hline
\end{tabular}

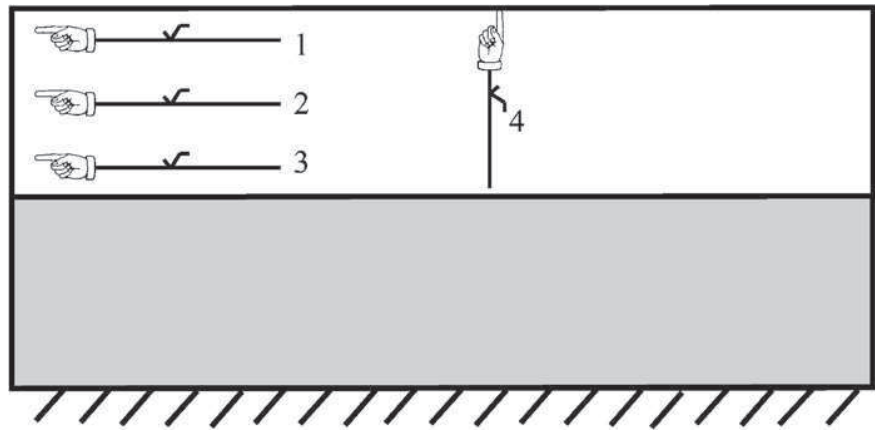

Fig. 7. Direction of roughness measurement

the cutting forces and the vibrations, the degradation of the wall is greater and can explain this slightly higher roughness. On the other hand, in direction 4, the surface quality is less degraded. In the following, roughness is observed only according to direction 1 .

Fig. 8 summarises the maximal roughness in direction 1. Poor surface finish can be noted for 24000 and $20500 \mathrm{rpm}$, with an $\mathrm{Ra}$ close to $7 \mu \mathrm{m}$ and an $\mathrm{Rt}$ of approximately $35 \mu \mathrm{m}$. The ratio between $\mathrm{Rt}$ and $\mathrm{Ra}$ is 5, which characterises a very irregular surface with large hollows and peaks. These two machinings are very unstable, and this is correlated with the stability lobes, see Fig. 8.

On the other hand, for $22250 \mathrm{rpm}$, the surface quality corresponds to industrial requirements, with $\mathrm{Ra}=3.2 \mu \mathrm{m}$ and $\mathrm{Rt}=10.9 \mu \mathrm{m}$. In this case, the ratio between $\mathrm{Rt}$ and Ra being close to 3 , the surface is more homogeneous and more regular than the previous ones. More stable machining can be found here.

In conclusion, the stability lobes are useful for thin wall milling optimisation. This section focuses on the maximal roughness (global analysis); however, the thin wall presents important variations in roughness. Now the surface finish of the sample obtained at $20500 \mathrm{rpm}$ will be studied more precisely. 


\subsection{Local analysis: roughness variation}

\subsubsection{Roughness analysis}

The surface finish obtained on the final part is not homogeneous; in fact several zones with very different surface qualities were shown. In this part, surface roughness of the part machined with $N=20500 \mathrm{rpm}$ was taken into consideration. Fig. 9 illustrates the various zones obtained. The picture of the machined wall can be divided

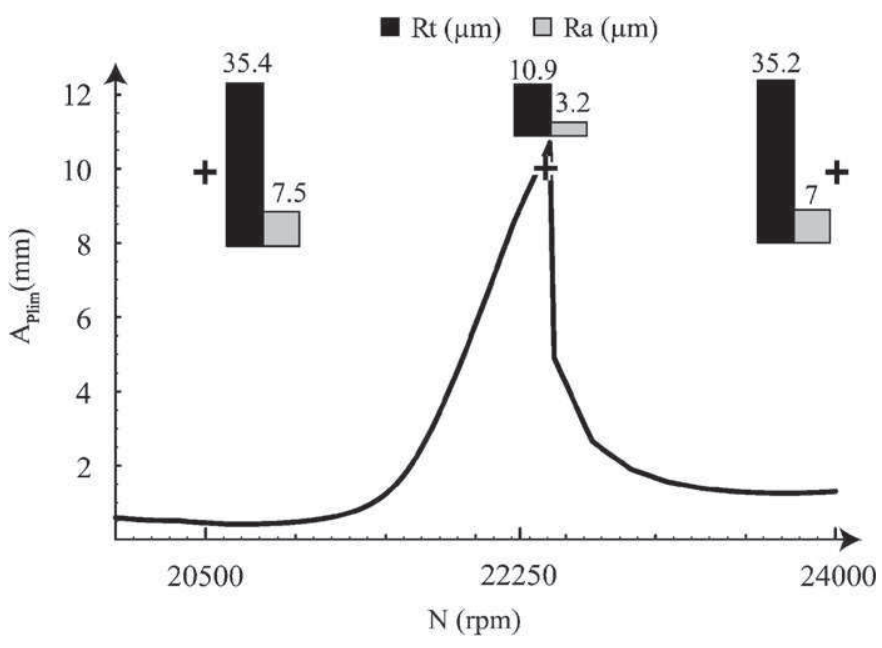

Fig. 8. Correlation between maximum roughness in direction 1 and stability chart. into 5 distinct zones. It is necessary to calculate the surface quality on each homogeneous zone. Roughness for each zone was measured, first by the stylus type instrument in $2 \mathrm{D}$, then by the $3 \mathrm{D}$ profilometre.

In Fig. 9, three important zones are visible. It is interesting to note that the $2 \mathrm{D}$ graphs do not have the same scales as the ordinates. The values of the roughness obtained by the stylus in 2D and the values obtained in 3D are equivalent; for example, for zone $2 \mathrm{Ra}=0.9 \mu \mathrm{m}$ and $\mathrm{sRa}=1.1 \mu \mathrm{m}$. But these two criteria cannot be compared because they are not the result of the same measurement. These two parameters are complementary: Ra qualifies profile in one direction only whereas sRa qualifies the machined surface.

Zone 2 is characterised by good surface quality with $\mathrm{Ra}=0.9 \mu \mathrm{m}, \mathrm{Rt}=2.7 \mu \mathrm{m}$ and $\mathrm{sRa}=1.1 \mu \mathrm{m}$. The ratio $\mathrm{Rt} / \mathrm{Ra}$ is close to 3, which implies a more homogeneous surface. These values are the optimum in peripheral milling. The 2D profile, Fig. 9(a), reveals peaks and hollows, the frequency of which is approximately $0.25 \mathrm{~mm}$, this value is much greater than the feed rate $(0.05 \mathrm{~mm} /$ tooth). This roughness is difficult to explain by only the eccentricity of the tool.

Zone 3 presents the most degraded zone characterised by $\mathrm{Ra}=7.5 \mu \mathrm{m}, \mathrm{Rt}=35.4 \mu \mathrm{m}$ and $\mathrm{sRa}=7.6 \mu \mathrm{m}$. In this case, the ratio between $\mathrm{Rt} / \mathrm{Ra}$ is close to 5 , with a more degraded surface characterised by peaks and hollows. The profile, Fig. 9(b), presents an undulation with a period of $0.7 \mathrm{~mm}$

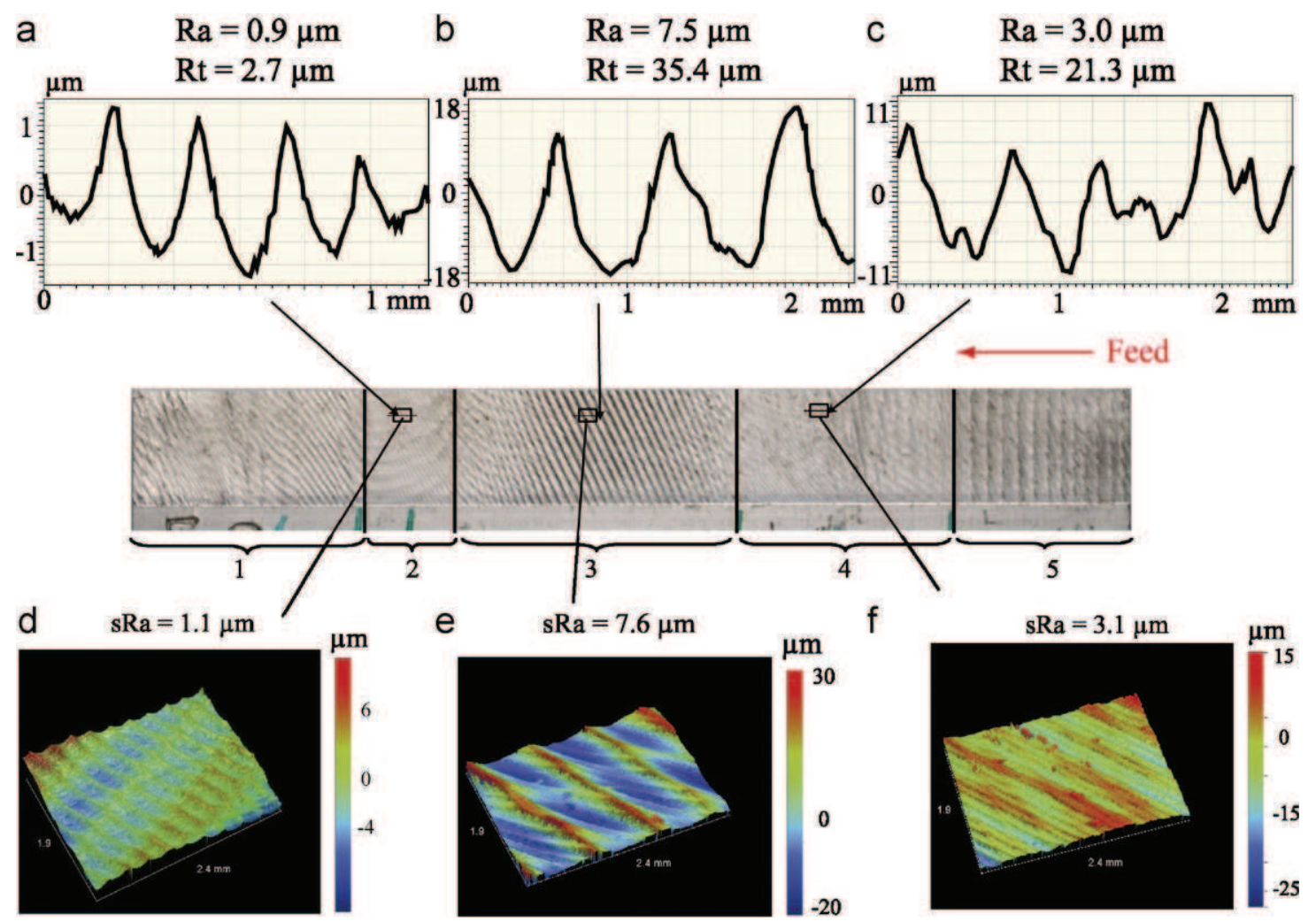

Fig. 9. Roughness variation along the machined wall at $20500 \mathrm{rpm}$. 
Table 4

Roughness (Ra, Rt) measurement for every zones in $\mu \mathrm{m}$

\begin{tabular}{|c|c|c|c|c|c|c|c|c|c|c|c|c|c|c|}
\hline \multirow[t]{3}{*}{ Spindle speed (rpm) } & \multicolumn{14}{|c|}{ Zones number } \\
\hline & \multicolumn{2}{|l|}{1} & \multicolumn{2}{|l|}{2} & \multicolumn{2}{|l|}{3} & \multicolumn{2}{|l|}{4} & \multicolumn{2}{|l|}{5} & \multicolumn{2}{|l|}{6} & \multicolumn{2}{|l|}{7} \\
\hline & $\mathrm{Ra}$ & $\mathrm{Rt}$ & $\mathrm{Ra}$ & $\mathrm{Rt}$ & $\mathrm{Ra}$ & $\mathrm{Rt}$ & $\mathrm{Ra}$ & $\mathrm{Rt}$ & $\mathrm{Ra}$ & $\mathrm{Rt}$ & $\mathrm{Ra}$ & $\mathrm{Rt}$ & $\mathrm{Ra}$ & $\mathrm{Rt}$ \\
\hline 24000 & 1.8 & 9.8 & 4.5 & 23.8 & 3.3 & 15.4 & 7.0 & 35.2 & 1.6 & 9.2 & 0.8 & 3.8 & 1.3 & 8.1 \\
\hline 22250 & 1.6 & 6.0 & 1.6 & 5.7 & 3.2 & 10.9 & 1.5 & 5.3 & 2.0 & 7.7 & 2.5 & 8.8 & 3.0 & 10.9 \\
\hline 20500 & 4.3 & 32.0 & 0.9 & 2.7 & 7.5 & 35.4 & 3.0 & 21.3 & 4.2 & 22.8 & - & - & - & - \\
\hline
\end{tabular}

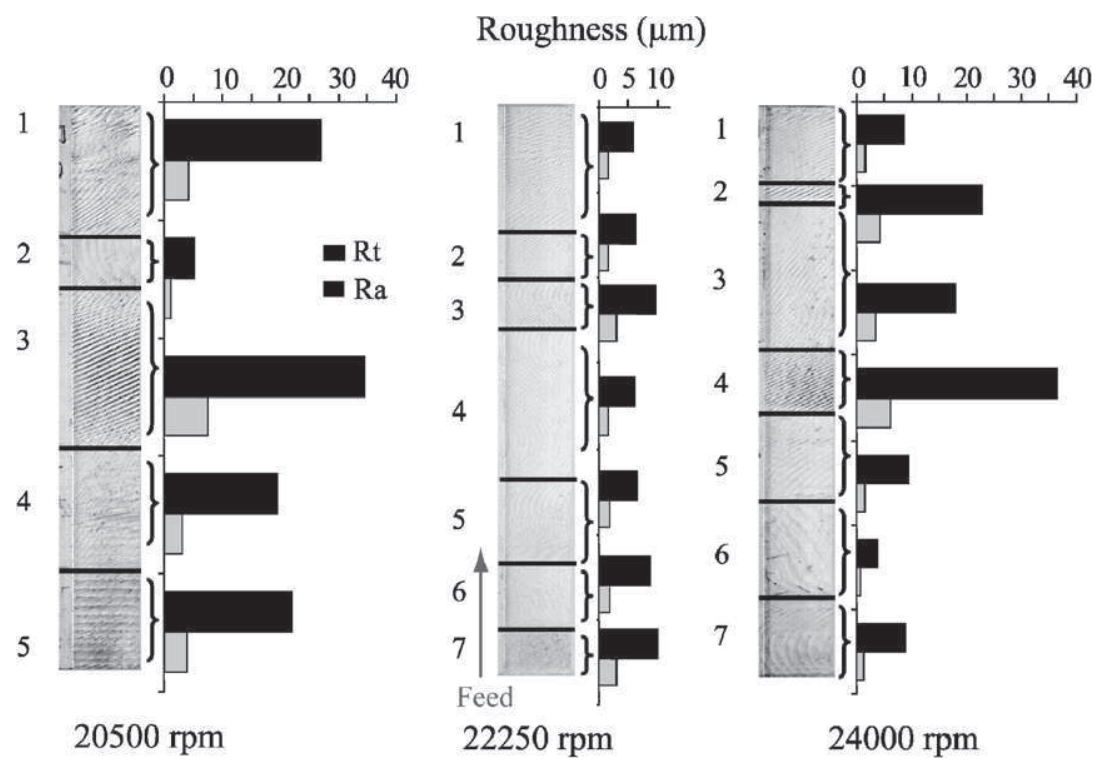

Fig. 10. Roughness for every zone at various spindle speed.

relative to strong vibration, because the tool leaves the cut periodically. The 3D photo, Fig. 9(e), reveals two different types of grooves:

- inclined elementary grooves of a constant angle related to the helix angle and

- larger grooves (observed previously), with a different inclination angle, linked to strong vibration that print this pattern on the surface.

Finally, zone 4 shows an intermediate zone with $\mathrm{Ra}=3 \mu \mathrm{m}, \mathrm{Rt}=21.3 \mu \mathrm{m}$ and $\mathrm{sRa}=3.1 \mu \mathrm{m}$. In this case, the $\mathrm{Ra}$ is close to industrial requirement $(3 \mu \mathrm{m})$, but the $\mathrm{Rt}$ is much larger than $11 \mu \mathrm{m}$. The $\mathrm{Ra}$ limitation is shown here, based on the area between the roughness profile and its mean line. This is also valid for the 3D parameter: sRa, which generalises the calculus along two axes. The ratio between $\mathrm{Rt} / \mathrm{Ra}$ is close to 7; there is a nonhomogeneous surface. The profile shape, Fig. 9(c), does not present the periodic wave, but reveals an irregular shape. It is an initial degradation of the surface roughness, characteristic of a transition zone.

The roughness results for all the spindle speeds are collected in Table 4. The machined samples with 22250 and
$24000 \mathrm{rpm}$ can be divided into 7 distinct zones. Fig. 10 shows the results in the form of a histogram. Here, it is clearly visible that on the same wall, there are various zones with very different surface qualities.

In conclusion, on the same part, different surface roughness are shown, although the cutting conditions and the dynamic characteristics are constant. This behaviour is evoked by the modelling in Section 3.3. In order to correlate the modelling, it is necessary to measure the vibrations during machining.

\subsubsection{Frequency vibration analysis}

In order to measure the vibration frequencies during machining, a laser vibrometre is used. This measuring device records the temporal signal of the velocity of the wall. It is possible to compute a fast Fourier transform (FFT) of the signal in order to obtain the vibration frequencies of the part during machining. Fig. 11 presents the various vibration frequencies associated with each zone for the machined sample at $20500 \mathrm{rpm}$.

Machining starts on zone 5 and finishes on zone 1. Thus, during the machining of zone 5, the part vibrated at a frequency of nearly $7000 \mathrm{~Hz}$; this chatter frequency is due to the second mode of the part. On the other hand, on zone 


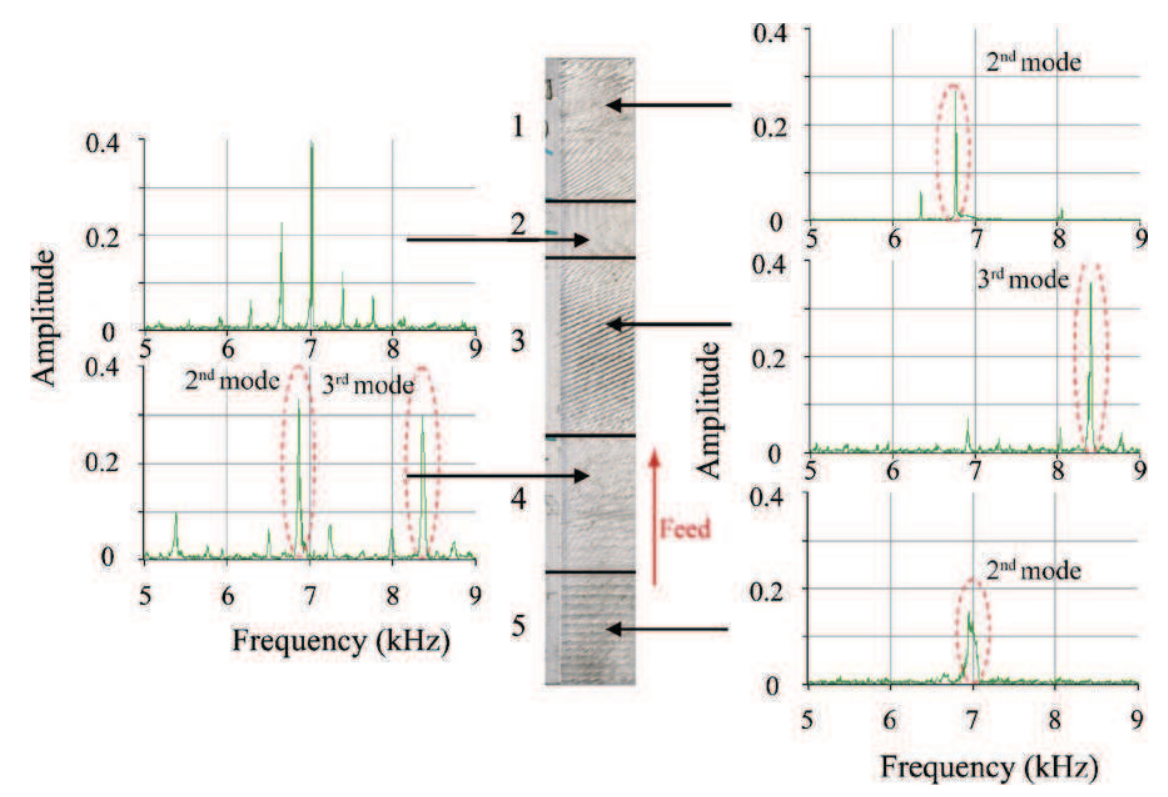

Fig. 11. FFT of the laser signal for each zone at $20500 \mathrm{rpm}$.

Simulated displacement

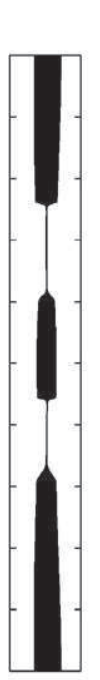

$\mathrm{u}(\mathrm{t})$

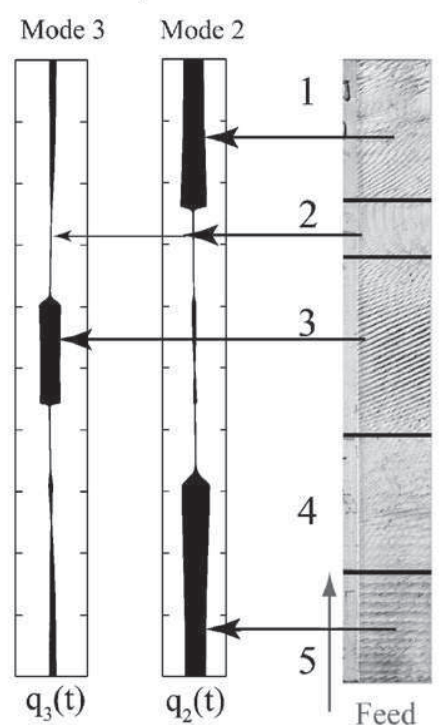

Measurement

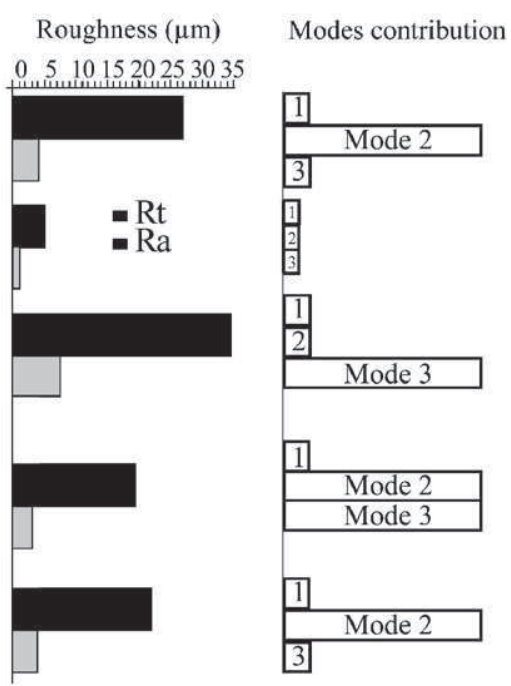

Fig. 12. Correlation between the modelling and the experiment at $20500 \mathrm{rpm}$.

4, the part vibrates according to two modes in two ways simultaneously; two peaks at 7000 and $8300 \mathrm{~Hz}$ are visible. It is a transition zone, quite difficult to analyse because the vibration mode is changing. In the same way, it is noted that on zone 3, the vibration frequency is approximately $8300 \mathrm{~Hz}$ - which is the third mode. In zone 2, there is no frequency clearly linked to the mode, but several harmonics, which are not the tooth frequency $(1366 \mathrm{~Hz})$, can be found. It is also a transition zone difficult to exploit and to measure by a point laser. Finally, in zone 1, the part vibrates in the second mode. The first mode does not intervene.

In conclusion, experiments show that the vibration frequency of the part evolves during machining. The part vibrates at several chatter frequencies separated by transition zones. The modelling presented in Section 3.3.3 is thus validated qualitatively.

\subsubsection{Correlation between experiment and modelling}

Now that roughness for each zone of the samples and vibration frequencies during machining are known, the results can be correlated with the modelling. Fig. 12 presents the modal displacement computed by the modelling, the experimental sample, the surface roughness, and the mode contributions for each zone.

For machining, starting with zone 5 , modelling predicts that the second mode vibrates like the experimental measurement. The measurement shows that zone 4 vibrates 
according to two modes. Zone 4 observed in Section 4.2.1, shows a degradation of surface roughness, now explained by the two-mode vibration. During this transition, the zone moves according to two modes, and the surface shape does not show a repetitive profile. The modelling does not present a particular mode vibration, whereas the experiment reveals the second and the third modes simultaneously. Zone 3 vibrates strongly only in third mode. The modelling shows this point by the great amplitude of the third mode. Zone 2 is also a transition between the third and second mode amplitudes. A dominant frequency is not visible; as the modelling predicts this zone is still difficult to correlate. Finally, zone 1 vibrates according to the second mode. The modelling is accurate in this respect, because the experimental zone corresponds to the modelling zone. Contrary to expectations, the link between the vibration amplitude and the surface roughness is too complex to give predictive values. It is possible to interpret only the surface roughness variation obtained after machining.

The largest discrepancies between the experiment and the modelling are observed in the transition zone positions. It is presently not clear what causes these discrepancies. Possible reasons could be: the linear cutting law, the simplified chip thickness calculation or the simplified ploughing effect. But, other calculations showed that the increase in the cutting coefficients has a beneficial effect on the position of the transition zones. According to the recent simulations [8], a nonlinear cutting law seems to be more accurate at low radial depth of cut.

In conclusion, the correlation between the modelling and the experiment is coherent. But there remain transition zones, which are difficult to model and to analyse by the various measurements. The simplified model proposes an interpretation of the surface quality variations observed during machining: the appearance and disappearance of the various modes is controlled by their modal shape (position of the nodes).

\section{Conclusions}

In this article, stability and variable surface roughness was investigated in the case of thin wall milling with multimode interactions. Based on both the simulation and experimental investigation, the following points are made clear.

(1) Stability lobes obtained by analytical approaches are useful for thin wall milling optimisation. However, the prevalence usually observed of a vibrations mode over the other modes, although these other modes should have strongly vibrated, is not explained without a nonlinear mode coupling.

(2) A simple numerical model able to obtain coherent vibration amplitudes is proposed. This model uses: the regenerative effect of the cut, the modal shape, the fact that the tool may leave the cut when the vibrations are too strong, and the ploughing effect. Each specificity is naturally linked to the thin wall milling and must be included in this model in order to obtain acceptable results.

(3) A simple explanation of the surface roughness variations along the workpiece is proposed: the vibration mode during machining is mainly controlled by the modal shape. The mode coupling effect is linked to the regenerative effect and gives an advantage to the mode, which started first, until a node of this mode is encountered.

(4) There is a strong relationship between surface roughness and vibration during machining. However, the link between the vibration amplitude and the surface roughness is too complex to give predictive values.

(5) The dynamic model presented here can be used and modified easily: the equations are clarified in the article, most of the parameters can be given by the machining properties and the resolution is carried out by a classical Matlab ${ }^{\circledR}$ routine.

(6) There is a reasonable correlation between the simulation and the experiment, but gaps remain related to: the linear cutting law, the simple ploughing effect.

\section{Acknowledgement}

The authors acknowledge the co-financial support of the European Union by means of the Interreg IIIa Action AEROSFIN (The Pyrenees Manufacturing Aeronautical Spanish-French Interregional Network).

\section{References}

[1] M.S. Fofana, K.C. Ee, I.S. Jawahir, Machining stability in turning operation when cutting with a progressively worn tool insert, Wear 255 (2003) 1395-1403.

[2] M.A. Davies, B. Balachandran, Impact dynamics in milling of thin walled structures, Nonlinear Dynamics 22 (2000) 375-392.

[3] S.A. Tobias, W. Fishwisck, A Theory of Regenerative Chatter, The Engineer, London, 1958.

[4] J. Tlusty, M. Polacek, The stability of machine tool against self exited vibrations in machining, in: Proceeding of the ASME, Production Engineering Research Conference, Pittsburgh, 1963.

[5] E. Budak, Y. Altintas, Analytical prediction of chatter stability in milling. Part I. General formulation, Transaction of the ASME, Journal of Dynamic Systems, Measurement, and Control 120 (1998) 22-30.

[6] E. Budak, Y. Altintas, Analytical prediction of chatter stability in milling. Part II. Application of the general formulation to common milling systems, Transaction of the ASME, Journal of Dynamic Systems, Measurement, and Control 120 (1998) 31-36.

[7] E. Budak, Mechanics and dynamics of milling thin walled structures, Ph.D. Thesis, University of British Columbia, 1994.

[8] F. Lapoujoulade, T. Mabrouki, K. Raïssi, Prédiction du comportement vibratoire du fraisage latéral de finition des pièces à parois minces, Mécanique et Industrie 3 (2002) 403-418.

[9] V. Thevenot, L. Arnaud, G. Dessein, G. Cazenave-Larroche, Influence of material removal on dynamic behavior of thin walled structure in peripheral milling, Machining Science and Technology 10 (2006) 275-287. 
[10] V. Thevenot, L. Arnaud, G. Dessein, G. Cazenave-Larroche, Integration of dynamic behaviour in stability lobes method: 3D lobes construction and application to thin walled structure milling, International Journal of Advanced Manufacturing Technology 27 (2006) 638-644.

[11] U. Bravo, O. Altuzarra, L.N. Lopez de Lacalle, J.A. Sanchez, F.J. Campa, Stability limits of milling considering the flexibility of the workpiece and the machine, International Journal of Machine Tools and Manufacture 45 (2005) 1669-1680.

[12] S. Herranz, F.J. Campa, L.N. Lopez de Lacalle, A. Rivero, A. Lamikiz, E. Ukar, J.A. Sanchez, U. Bravo, The milling of airframe components with low rigidity: a general approach to avoid static and dynamic problems, Proceedings of the Institution of Mechanical Engineers, Part B: Journal of Engineering Manufacture 219 (2005) 789-801.

[13] M.A. Davies, J.R. Pratt, B. Dutterer, T.J. Burns, Stability prediction for low radial immersion milling, Transaction of the ASME, Journal of Manufacturing Science and Engineering 124 (2002) 217-225.

[14] J. Gradisek, M. Kalveram, T. Insperger, K. Weinert, G. Stepan, E. Govekar, I. Grabec, On stability prediction for milling, International Journal of Machine Tools and Manufacture 45 (2005) 769-781.

[15] M. Zatarain, J. Munoa, G. Peigné, T. Insperger, Analysis of the influence of mill helix angle on chatter stability, Annals of the CIRP 55 (2006) 365-368.
[16] T. Insperger, J. Munoa, M. Zatarain, G. Peigné, Unstable islands in the stability chart of milling processes due to the helix angle, in: Proceedings of the Second CIRP International Conference on High Performance Cutting, Vancouver, Canada, 2006.

[17] P.G. Benardos, G.C. Vosniakos, Predicting surface roughness in machining: a review, International Journal of Machine Tools and Manufacture 43 (2003) 833-844.

[18] D. Montgomery, Y. Altintas, Mechanism of cutting force and surface generation in dynamic milling, Transaction of the ASME, Journal of Engineering for Industry 113 (1991) 160-168.

[19] S. Assouline, E. Beauchesne, G. Coffignal, P. Lorong, A. Marty, Simulation numérique de l'usinage à l'échelle macroscopique : modèles dynamiques de la pièce, Mécanique et Industrie 3 (2002) 389-402.

[20] H. Paris, G. Peigné, R. Mayer, Surface shape prediction in high speed milling, International Journal of Machine Tools and Manufacture 44 (2004) $1567-1576$.

[21] N. Corduan, J.P. Costes, F. Lapoujoulade, Modelling and experimental approach of milling stability: application to thin walled parts, in: Proceedings of the Fifth International Conference on High Speed Machining, Metz, France, 2006.

[22] M.P. Groover, Fundamentals of Modern Manufacturing: Materials, Processes, and Systems, Prentice-Hall, Englewood Cliffs, NJ, 1996.

[23] K.J. Stout, Development of Methods for the Characterisation of Roughness in Three Dimensions, Penton Press, London, 2000. 